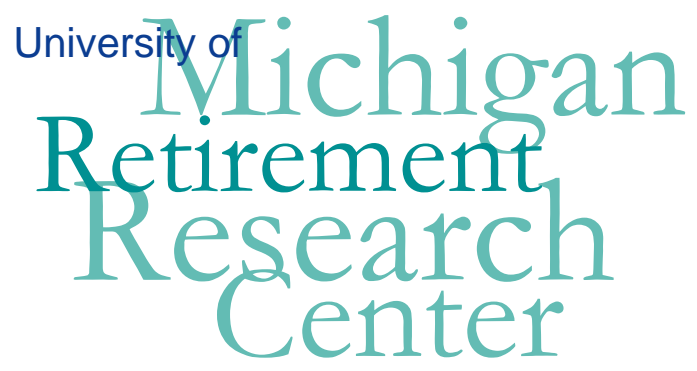

Working Paper

WP 2005-107

\title{
Technological Progress and Worker Productivity at Different Ages
} John Laitner and Dmitriy Stolyarov

\begin{tabular}{|l|l|l|}
\hline $\mathrm{M}$ & $\mathrm{R}$ \\
\hline $\mathrm{R}$ & $\mathrm{C}$ & \\
\hline
\end{tabular}$\quad$ Project \#: UM05-04 


\title{
“Technological Progress and Worker Productivity at Different Ages”
}

\author{
John Laitner \\ The University of Michigan \\ Dmitriy Stolyarov \\ The University of Michigan
}

December 2005

\author{
Michigan Retirement Research Center \\ University of Michigan \\ P.O. Box 1248 \\ Ann Arbor, MI 48104 \\ http://www.mrrc.isr.umich.edu/
}

(734) 615-0422

\section{Acknowledgements}

This work was supported by a grant from the Social Security Administration through the Michigan Retirement Research Center (Grant \# 10-P-98358-5). The findings and conclusions expressed are solely those of the author and do not represent the views of the Social Security Administration, any agency of the Federal government, or the Michigan Retirement Research Center.

\section{Regents of the University of Michigan}

David A. Brandon, Ann Arbor; Laurence B. Deitch, Bingham Farms; Olivia P. Maynard, Goodrich; Rebecca McGowan, Ann Arbor; Andrea Fischer Newman, Ann Arbor; Andrew C. Richner, Grosse Pointe Park; S. Martin Taylor, Gross Pointe Farms; Katherine E. White, Ann Arbor; Mary Sue Coleman, ex officio 


\title{
Technological Progress and Worker Productivity at Different Ages
}

\author{
John Laitner \\ Dmitriy Stolyarov
}

\begin{abstract}
Economists have long thought of technological progress as a primary determinant of rising living standards over time. One might think of technological progress as increasing the "effectiveness" of labor, thereby raising the amount of output that each unit of labor can produce. The purpose of this paper is to ask whether, as an empirical matter, technological progress increases the productivity of workers evenly, or whether it augments the effectiveness of young workers the most. As low birthrates and increases in longevity lead to an "aging" of the population, the productivity of older workers relative to younger workers is likely to become an ever more important issue.

Analyzing data from the decennial Censuses and annual data from the Current Population Survey, this paper draws three tentative conclusions. First, we find that the "aging" of the U.S. work force seems more likely to increase aggregate productivity - by raising the proportion of laborers with sizable accumulations of human capital from experience than to decrease it - by slowing the adoption rate for innovations. Our preliminary estimates imply that the latter effect is of modest magnitude. Second, since our preliminary estimates point to "general" rather than "specific" technological progress, each household faces a problem of having to predict the course of technological progress over its life span. This means that households face more risk than otherwise, and it complicates the specification of the life-cycle model that analysts should employ. Third, when we disaggregate across education groups, the groups show quite unequal benefits from technological progress after 1980, and this may lead to further challenges in modeling household behavior.
\end{abstract}

\section{Authors' Acknowledgements}

Yuriy Gorodnichenko provided excellent research assistance to the authors. 


\section{Introduction}

Economic analysis emphasizes the importance of technological change as a determinant of living standards in the long run. A number of the key studies on this topic are due to Solow [1956, 1957, 1960]. In Solow's [1956] basic framework, expansion of the labor force, accumulation of physical capital, and improvements in technology each contribute to a nation's growth; however, the model has the strong implication that it is technological progress alone that governs the trajectory of living standards over the very long run. In particular, an economy with no technological progress has stationary living standards; and, if one economy has technological progress that is, say, twice as fast as another, the average standard of living in the first will grow twice as rapidly over the long run as in the second. In Solow, and in subsequent studies, technological change operates by raising the "effectiveness" of labor, thereby raising the amount of output that each unit of labor can produce. $^{1}$ The purpose of the present paper is to ask the following question about this process: As an empirical matter, does technological progress increase the productivity of workers evenly, or does it impact young workers the most?

Due to low birth rates and falling mortality, most OECD countries have aging work forces - in the sense that their proportion of older relative to younger workers is rising (e.g., Nyce and Schieber [2005]). Concerns about the implications of global aging are one motive for studying the process through which technological progress affects worker productivity. At least two questions arise in this regard. (i) If older workers are less able, or less willing, to absorb new technologies than younger workers, might aging slow the diffusion of new technologies in an economy? (ii) If older workers are inherently less productive - perhaps because of declining health status - might aging, in an even more direct way, reduce an economy's average per capita output? As our empirical strategy requires joint consideration of (i)-(ii), this paper investigates both.

A second motive for our study is the key role that lifetime earning patterns play in economists' so-called life-cycle model of behavior. The model confronts the difficult task of explaining household consumption, saving, and labor supply decisions, and it is a mainstay of economists' analysis of public policy issues such as Social Security and incometax reform. Both the effect of technological progress on productivity at different ages and inherent differences in productivity at different ages are potentially significant to outcomes for the life-cycle model.

This paper uses U.S. Census data 1950-2000 and Current Population Survey data 1967-2000 on earnings at various ages and education levels. The paper's organization

\footnotetext{
1 See Burmeister and Dobell [1969].
} 
is as follows. Section 2 clarifies the forms that productivity differences at different ages could take, and Section 3 systematically examines why differences among the forms are potentially so important. Section 4 presents our evidence and results. Section 5 concludes.

\section{Worker Productivity}

Assuming that employers pay wages proportional to each worker's productivity, the following discussion illustrates our specific concerns. ${ }^{2}$

Figure 1 shows the hypothetical wage rate of worker A from the age at which he starts work, say, $s=0$ (which, in practice, might correspond to chronological age 25, for instance), to the age at which he retires, say, $s=R$. For the sake of later comparisons, assume that the economy's technology is stationary during worker A's lifetime. Worker A's age 0 wage, say, $w_{0}^{A}$, reflects the his education, his health status, his natural abilities, and the technology existing as he starts his career. Following Becker [1974], call the first the worker's "human capital from schooling." Despite the stationary technology, we would expect worker A's wage rate to rise with age, at least in his youth, while he accumulates experience and obtains on-the-job training. Call the sum of his accumulated knowledge from these sources his "human capital from experience."

In Figure 1, worker A's wage profile rises to a peak in middle age and then falls. The decline might stem from deteriorating health status. Or, it might follow from agerelated changes in human capital. In particular, as a worker ages, day-to-day challenges presumably contain less and less novelty; thus, his accumulation of human capital from experience might slow down. And, to the extent that human capital from experience arises from training that is costly for the worker or his employer, the shorter time horizon until retirement of older workers may slow accumulation. It is also true that because older workers tend to have a higher base of existing human capital than their younger colleagues, incremental benefits from training may be smaller; hence, presumably more training takes place in youth. Finally, even in an economy with a stationary technology, individuals tend to move through a succession of jobs - from promotions, firm bankruptcies, production changes due to variability of consumer taste, geographical displacements, etc. - and with each move, part of the individual's existing knowledge becomes less valuable, with the losses tending to be greater at older ages, when human capital is larger. Even apart from possible changes in health status, worker A's wage profile will, therefore, tend to level off or decline late in life.

2 This paper makes the neoclassical assumption that in practice, each worker's wage is proportional to his productivity. It does not explore alternative models - such as seniority wages - which one might employ in interpreting U.S. data. 
In this paper, we say that the wage profile of worker A manifests his "productivity independent of technological change" at different ages. We next depict the possible ways in which technological progress may raise a worker's productivity. We refer to these enhancements as "productivity augmentation from technological change."

Suppose that after the retirement of worker $\mathrm{A}$, technological progress at rate $x$ percent per year commences for the economy, and sometime later, worker B begins his career. Figure 1 presents a hypothetical lifetime wage profile for worker B. For ease of comparison, suppose worker B has the same innate abilities, the same health status, and the same number of years of schooling as worker A had when he started his career; however, because of technological progress between generations, worker B has higher effectiveness as he begins work, and he consequently starts with a higher wage, $w_{0}^{B}>w_{0}^{A}$. Although the magnitude of $w_{0}^{B}-w_{0}^{A}$ is of interest, we also want to know how the difference between wage profiles for workers A and B changes with the workers' experience - recalling that B lives through an era of continuous technological progress, whereas A did not.

First, consider the case that technological change is "specific" to human capital from schooling. Solow [1960] studied a model in which each machine forever "embodied" the technology prevalent at the moment it was built - e.g., an office copier machine built in 2005 is superior to one built in 1985 and costing, at the time, the same amount; furthermore, it is quite possible that in order to gain the new features and quality advantages potentially available in 2005, rather than retrofit an old copier with current innovations, one must purchase a new machine. If human capital from schooling "embodies" the technology of its vintage in the same way, technological change that continues in the economy after worker B begins his career may not affect his productivity. In this case, worker B's wage advantage over worker $A$ would tend to be uniform at all ages. Comparison of wage profiles A and B in Figure 1, with worker B's profile starting at $w_{0}^{B}$ and ending at $w_{R}^{B}$, illustrates the case of "specific" technological change.

In the other polar case, technological progress is "general" in the sense that it can change a worker's effectiveness regardless of the worker's age. Worker $\mathrm{C}$ in Figure 1 illustrates. Worker $\mathrm{C}$ starts at wage $w_{0}^{C}$ exceeding $w_{0}^{A}$ because of technological progress between their starting dates. Worker C's productivity growth proceeds as he ages because technological progress is continuous and worker $\mathrm{C}$ is continuously able to benefit from it. (In Solow's terminology, labor-augmenting progress is "disembodied.") As worker C follows the profile from $w_{0}^{C}$ to $w_{R}^{C}$, technological progress within his lifetime steepens his profile, causing his relative advantage over A to expand with age; consequently, 


$$
\frac{w_{0}^{C}}{w_{0}^{A}}<\frac{w_{R}^{C}}{w_{R}^{A}} .
$$

Intermediate cases are, of course, possible, and, perhaps, likely. For example, young workers may generally be more open minded about change, but their flexibility may diminish with age. In Figure 1, worker $\mathrm{C}$ may start with a higher wage than $\mathrm{A}$, the difference may expand at early ages as $\mathrm{C}$ absorbs the continuing technological progress, but the proportionate difference beyond some age may become constant as $\mathrm{C}$ loses his willingness/ability to take advantage of innovations. A description depending on economics rather than physiology could be as follows. Although older workers might be just as good at adopting innovations, new knowledge is more likely to displace existing knowledge (i.e., existing human capital) in the case of an older worker. If adopting an innovation is akin to making an investment, while the gross and net investment of adopting a given innovation may be nearly equal for a young worker, the net investment may be considerably smaller that the gross for an experienced worker. This may render the net productivity gain from acquiring new knowledge considerably smaller, leading to diminished investment on the part of older workers.

\section{Importance}

While there are many reasons why workers' productivity, and their ability to continuously renew and increase it, at different ages is potentially important, this section focuses on two. Namely, we consider the possible impact of global aging on societies' overall productivity, and we evaluate the possible consequences of the nature of productivity changes over the life cycle for the way that we should model the saving, consumption, and retirement behavior of households and the risks that they face.

Global aging and labor force productivity. Falling mortality and declining birth rates are causing the populations and work forces of OECD countries to age. This raises concerns about future productivity. Nyce and Schieber [2005] write,

"There appears to be a fairly strong inverse relationship between entrepreneurial activities and aged dependency [ratios] ... This suggests that aging societies may be less likely to engage in creative destructive activities that accelerate the adoption of technological innovations and can ameliorate the effects of capital deepening on rates of return." [p. 255]

To take a second example, discussing the work force in Germany, Borsch-Supan [2004] writes, 
"This fundamental change in the age structure of the working population will have profound effects on the microeconomics and the sociology of the labor market. The most important - and most controversial - aspect is the potential effect on labor productivity. If labor productivity is age dependent, a shift in the age structure will also bring about a change in aggregate productivity, even if age-specific productivity were to remain constant. [p. 16]

The first quotation warns that an aging work force may be less eager, or less adept, at taking advantage of new technologies; the second warns that, apart from technological change, to the extent that older workers are less productive, aging of a country's work force may lower the nation's average product of labor. This subsection examines both points.

Suppose that we think of the "effective labor supply" in the economy, $E_{t}$, as the product of three terms. Let the height of the lifetime wage profile of worker A in Figure 1, which registers inherent productivity at different ages $s$, be $p(s)$. As stated in Section 2, this gives the "productivity independent of technological change" for workers. Then we subdivide effective labor as follows:

$$
E_{t}=A_{t}^{A} \cdot A_{t}^{I} \cdot L_{t}
$$

where the natural labor supply is

$$
L_{t} \equiv \int_{0}^{R} N_{t} \cdot e^{-n \cdot s} d s,
$$

with $N_{t}$ the number of labor force entrants at time $t, n$ the rate of population growth (so that $N_{t} \cdot e^{-n \cdot s}$ is the number of entrants at time $t-s$ ), and $R$ the age of retirement; the average productivity per worker independent of technological progress is

$$
A_{t}^{I} \equiv \frac{\int_{0}^{R} p(s) \cdot N_{t} \cdot e^{-n \cdot s} d s}{\int_{0}^{R} N_{t} \cdot e^{-n \cdot s} d s}
$$

and, the augmentation of worker productivity from technological change is

$$
A_{t}^{A}=A_{t}^{A G} \equiv \frac{\int_{0}^{R} e^{g \cdot t} \cdot p(s) \cdot N_{t} \cdot e^{-n \cdot s} d s}{\int_{0}^{R} p(s) \cdot N_{t} \cdot e^{-n \cdot s} d s}
$$

if technological progress is "general" but 


$$
A_{t}^{A}=A_{t}^{A S} \equiv \frac{\int_{0}^{R} e^{g \cdot(t-s)} \cdot p(s) \cdot N \cdot e^{-n \cdot s} d s}{\int_{0}^{R} p(s) \cdot N \cdot e^{-n \cdot s} d s}
$$

if progress is "specific."

Consider average productivity independent of lifetime technological progress, $A_{t}^{I}$. A lower birth rate raises the proportion of older workers in the labor force at any $t$; hence, we study the effect of global aging on $A_{t}^{I}$ by examining what happens if we lower the birth rate. To gauge the latter, we check the sign of

$$
\frac{d A_{t}^{I}}{d n}=-\frac{\int_{0}^{R} s \cdot N_{t} \cdot e^{-n \cdot s} \cdot p(s) d s}{\int_{0}^{R} N_{t} \cdot e^{-n \cdot s} d s}+\frac{\int_{0}^{R} N_{t} \cdot e^{-n \cdot s} \cdot p(s) d s}{\int_{0}^{R} N_{t} \cdot e^{-n \cdot s} d s} \cdot \frac{\int_{0}^{R} s \cdot N_{t} \cdot e^{-n \cdot s} d s}{\int_{0}^{R} N_{t} \cdot e^{-n \cdot s} d s} .
$$

If the sign is positive, a lower birth rate lowers productivity independent of lifetime technological progress, and vice versa.

With slight manipulation, equation (3) yields

$$
\operatorname{sgn}\left\{\frac{d A_{t}^{I}}{d n}\right\}=\operatorname{sgn}\left\{-\frac{\int_{0}^{R} s \cdot N_{t} \cdot e^{-n \cdot s} \cdot p(s) d s}{\int_{0}^{R} N_{t} \cdot e^{-n \cdot s} \cdot p(s) d s}+\frac{\int_{0}^{R} s \cdot N_{t} \cdot e^{-n \cdot s} d s}{\int_{0}^{R} N_{t} \cdot e^{-n \cdot s} d s}\right\} .
$$

If productivity $p(s)$ rises with age at every age, one could show that the right-hand side of (4) is negative - the first term on the right side gives the average age of workers in productivity weighted units; the second is the conventional average age; so, when $p(s)$ increases in $s$ for all ages, older workers are typically more productive, and the productivity weighted average age must be higher than the conventional average. In that case, aging increases average productivity $A_{t}^{I}$.

Figure 1, and indeed most measurements in the literature, show $p(s)$ declining at an advanced age. Then the sign in (4) is not clear cut from a theoretical perspective. Nevertheless, if $\bar{s}$ is the average age in the labor force, i.e., if

$$
\bar{s} \equiv \frac{\int_{0}^{R} s \cdot N_{t} \cdot e^{-n \cdot s} d s}{\int_{0}^{R} N_{t} \cdot e^{-n \cdot s} d s}
$$

and if

$$
p(s) \geq 0 \quad \text { all } \quad s, \quad \frac{d p(s)}{d s}>0 \quad \text { all } \quad s<\bar{s}, \quad \text { and } \quad p(\bar{s}) \leq p(s) \quad \text { all } \quad s \geq \bar{s}
$$


the sign of (4) remains unambiguously negative.

Proposition 1. Let $\bar{s}$ be the average age for workers. Suppose condition (5) holds. Then

$$
\frac{d A_{t}}{d n}<0
$$

Proof: See Appendix.

Proposition 1 subsumes the case in which $p(s)$ is increasing all $s$, and condition (5) may hold in empirically relevant circumstances.

If condition (5) does hold, Proposition 1 shows that, contrary to some fears in the literature, global aging may tend to raise average productivity. The idea is that a low birth rate and falling mortality give a country a more experienced work force, for which output per worker tends to be higher.

Turn next to the issue of labor's ability at different ages to take advantage of innovations. If human capital is "general" and technological progress proceeds at rate $g$, the proportionate effect of more rapid technological progress is the derivative of the logarithm of $A_{t}^{A G}$ :

$$
\frac{d \ln \left(A_{t}^{A G}\right)}{d g}=t
$$

This effect cumulates over time. With "general" progress, it is insensitive to demography — in particular, because technological progress affects all ages symmetrically, we have

$$
\frac{d^{2} \ln \left(A_{t}^{A G}\right)}{d n d g}=0
$$

Alternatively, suppose that human capital is "specific," so that the time-t productivity of workers of age $s$ depends on the state of technology when they entered the labor force, $e^{g \cdot(t-s)}$. Then we have

$$
\frac{d \ln \left(A_{t}^{A S}\right)}{d g}=t-\frac{\int_{0}^{R} s \cdot e^{g \cdot(t-s)} \cdot N_{t} \cdot e^{-n \cdot s} d s}{\int_{0}^{R} e^{g \cdot(t-s)} \cdot N_{t} \cdot e^{-n \cdot s} d s} \equiv t-\tilde{s}
$$

where the second term on the far right is the average age of the productivity-weighted labor force, which we designate as $\tilde{s}$. Canceling $N_{t}$ and $e^{g \cdot t}$ from the numerator and denominator of $\tilde{s}$, we can see that $\tilde{s}$ is independent of time. In other words, although the enhancement of the "effectiveness" of the labor force from technological progress cumulates through time 
(as in the case with "general" progress), the degree to which the best technology currently available has diffused through the economy is less by a constant amount in every year. This means that the ratio $A_{t}^{A S} / A_{t}^{A G}$ is a constant less than one. We have

$$
\begin{aligned}
\frac{d^{2} \ln \left(A_{t}^{A S}\right)}{d n d g}= & \frac{\int_{0}^{R} s^{2} \cdot e^{g \cdot(t-s)} \cdot N_{t} \cdot e^{-n \cdot s} d s}{\int_{0}^{R} e^{g \cdot(t-s)} \cdot N_{t} \cdot e^{-n \cdot s} d s} \\
& \quad-\frac{\int_{0}^{R} s \cdot e^{g \cdot(t-s)} \cdot N_{t} \cdot e^{-n \cdot s} d s}{\int_{0}^{R} e^{g \cdot(t-s)} \cdot N_{t} \cdot e^{-n \cdot s} d s} \cdot \frac{\int_{0}^{R} s \cdot e^{g \cdot(t-s)} \cdot N_{t} \cdot e^{-n \cdot s} d s}{\int_{0}^{R} e^{g \cdot(t-s)} \cdot N_{t} \cdot e^{-n \cdot s} d s} \\
= & \frac{\int_{0}^{R}(s-\tilde{s})^{2} \cdot e^{g \cdot(t-s)} \cdot N_{t} \cdot e^{-n \cdot s} d s}{\int_{0}^{R} e^{g \cdot(t-s)} \cdot N_{t} \cdot e^{-n \cdot s} d s} \geq 0 .
\end{aligned}
$$

Hence, aging, which is equivalent here to lowering $n$, makes the loss from slow diffusion greater.

We can see that for "productivity augmentation from technological change," the distinction between "specific" and "general" technological progress is critical. If progress is "specific," expression (7) shows that aging of the work force will lead to reduced productivity because new knowledge diffuses through new entrants to the labor force. If, on the other hand, progress is "general," the ratio of old to young workers is irrelevant to the economy's ability to profit from innovations quickly.

To summarize,

Proposition 2. If technological progress is "general," aging of the labor force does not influence the positive effect of $g$ on the rate of growth of $A_{t}^{A}$ -

$$
\frac{d^{2} A_{t}^{A G}}{d d n d g}=0
$$

If, on the other hand, technological progress is "specific," aging of the labor force diminishes the positive effect of technological change on the effectiveness of labor -

$$
\frac{d^{2} A_{t}^{A S}}{d n d g} \geq 0
$$

Proof: See preceding text.

Life cycle saving. The primary framework that economists use to study households' consumption, saving, and retirement decisions, and, in particular, potential effects on the 
latter from public policy changes, is the so-called "life-cycle model." The nature and the rate of technological progress are very important to the model's functioning.

In his Nobel Prize lecture about the life-cycle model (a model, which he had played a large role in developing), Modigliani [1986] implicitly assumes that technological progress is "specific." According to the model, a household saves in youth and, especially, middle age in order to be able to maintain its consumption after retirement. In the most basic version of the model, households do not receive inheritances or leave bequests. Figure 2 presents the general pattern that the model predicts. The earnings of the illustrated household, say, household $\mathrm{A}$, are $e_{s}^{A}$ at age $s$, its consumption flow is $c_{s}^{A}$, and its stock of assets (net of debt) is $a_{s}^{A}$. The household consumes less than its earnings prior to retirement so that it can maintain its consumption during retirement by drawing down its stock of assets. The household chooses its retirement age $R$ in view of its tradeoff between more years of earnings and the corresponding sacrifice of leisure.

Suppose that technological progress begins after household A retires. Assume that the economy's technology is stationary during household A's lifetime. Thereafter, technological progress begins. We compare the life-cycles of households B and C, which start later, to A.

Suppose technological progress is "specific." Although household C's earning profile is higher (because of a more recent start) than A's, the two profiles are parallel with respect to age. See Figure 3. Household $\mathrm{C}$ can adjust its consumption and asset profiles upward in proportion to its higher earnings. Retirement age need not change. This is the case that Modigliani [1986] emphasizes.

In Figure 2, technological progress is "general;" thus, household B's earning profile is not only higher than A's, but it is also steeper. If household B has full information, it will be especially anxious to do its heaviest saving in middle age, when its earnings are much higher than in youth. For given total of lifetime earnings, household B, to take full advantage of relatively high wages late in life, may choose to retire later than household A.

Section 4 will show that, in fact, U.S. productivity growth is quite uneven. In addition to high frequency fluctuations, it is possible to see episodic changes with decadal time spans. Specifically, productivity growth was rapid 1950-70, slow 1970-1990, and, perhaps, faster 1990-2000.

This paper's focus has important bearing on the life-cycle model in several dimensions.

First, the shape of the lifetime earning profiles, including the effect of lifetime technological change on them, is one key determinant of the aggregate amount of life-cycle saving and wealth accumulation that the model predicts. Modigliani thought that a higher rate of specific technological progress would tend to increase aggregate saving, say, as a percent 
of total earnings, by lowering the productivity-weighted average age of the population. His reasoning was that the life-cycle model predicts positive saving for a household in youth and negative in old age, past retirement. Modigliani, however, treated the saving rate of households as roughly constant from age 0 to $R$. If, in practice, household saving rates are highest in middle age, his argument loses its force. When technological progress is "general," the nonlinearity of saving rates prior to retirement is likely to be especially great.

Aggregate wealth accumulation is at least as interesting. Here the effect of productivity weighting is always ambiguous because the life-cycle model predicts low wealth for young and old households but high wealth for ages near retirement. If "general" technological progress leads households not to acquire wealth until advanced middle age, it could cause aggregate life-cycle accumulation to be lower (in proportion, say, to total earnings) when progress is more rapid.

Unfortunately, the connection between technological progress and aggregate saving and wealth accumulation in the life-cycle model is complicated. Future versions of this paper accordingly will present calibrated simulations.

A second issue for life-cycle analysis is the potential planning problem that episodic variability in the rate of technological progress creates for individual households. If progress is "specific" in terms of its effect on labor, such problems are likely to be minimal. With "specific" progress, a household discovers the height of its earning profile early in its career, and the shape is about the same in every generation; hence, a household's uncertainty is resolved at a young age. If, on the other hand, technological change is "general," a young household does not know the shape or the eventual height of its earning profile. If progress during its lifetime turns out to be rapid, it will exit middle age with pleasant options: it may retire early, decide to leave a bequest, and/or raise its consumption level. Conversely, if technological change is slower than expected, a household's options late in life are likely to be unappealing: the household must work longer, immediately cut its consumption, or cut its consumption a great deal after retirement.

The implications of this paper's next section for household difficulties in planning seem unambiguous: for a given degree of variability in technological progress, individual households face more risk if technological progress is "general" than if it is "specific." There are corresponding implications for how one should set up a life-cycle model: if technological progress is "general," in practice a household will face risk about the shape of its lifetime earning profile and the risk will tend to be uninsurable since it depends upon aggregative technology shocks; however, if progress is "specific," a household's risk will dissolve early in its youth, and a deterministic framework of analysis may suffice. 


\section{Results}

After briefly describing our data and statistical model, this section presents preliminary results.

Data. This paper uses U.S. Census data 1950, 60, 70, 80, 90, 2000 (i.e., PUMS data) from

$$
\text { http : //www.ipums.umn.edu/usa/ }
$$

and U.S. Current Population Survey data (i.e., CPS data) 1967, 68,..., 99, 2000 from

$$
\text { http : //www.nber.org/data/current-population - survey - data.html . }
$$

We employ wage and salary data on white males for individual ages 25-60 and for the individual education categories of high school, some college, and college/more. We consider only full-time workers, using their annual earnings as our dependent variable $w$ below. Our sample size from the PUMS is $1,205,824$; from the CPS, it is 619,629 .

This paper adjusts figures from each year in three ways. We make proportional adjustments for the difference between employee compensation and wages/salaries (see NIPA table 2.1, rows 2-3) and for the difference between compensation accruals and disbursements (see NIPA table 1.7.5, row 23). ${ }^{3}$ Due to growth in employer provided health insurance and pension benefits, the first adjustment is sizable, especially for 1970-80. The second adjustment, on the other hand, is small. Finally, we deflate with the GDP price index (see NIPA table 1.1.4, row 1).

$\underline{\text { Regression specification. }}$ Our basic statistical model provides a three-part description of male earnings.

Suppose that the compensation of worker $i$, of age $s$ and education $e$, at time $t$ is $w_{\text {iest }}$. As stated, this analysis considers three education groups: high school, some college, and college (and more). Assuming that members of the groups begin work at age 18, 20, and 22 , respectively, we calculate the experience $x$ for each worker. If, for instance, $e=$ "high

3 The NIPA series come from http : //www.bea.doc.gov/bea/dn/nipaweb/SelectTable.asp?Selected $=N$. 
school" for the worker above, his experience is $x=s-18$. In this way, we convert $w_{\text {iest }}$ to $w_{\text {iext }}$.

We divide $\ln \left(w_{\text {iext }}\right)$ into three components. The first captures a fixed effect associated with education together with an experience profile registering what Section 2 calls "productivity independent of technological change." This paper's specification of the first component is

$$
\gamma_{0}^{e}+\gamma_{1}^{e} \cdot x+\gamma_{2}^{e} \cdot \frac{x^{2}}{10}+\gamma_{3}^{e} \cdot \frac{x^{3}}{100}+\gamma_{4}^{e} \cdot \frac{x^{4}}{1000}
$$

The fixed effect is $\gamma_{0}^{e}$, with normalization $\gamma_{0}^{H S}=0$. The remaining polynomial terms capture the experience profile's shape, which may differ for different education groups. A maintained assumption is that the set of gammas for each education group is time invariant.

The second component of our regression equation for $\ln \left(w_{\text {iest }}\right)$ encompasses the effect of technological change at each experience level — what Section 2 calls "productivity augmentation from technological change." This paper's specification is

$$
\theta_{0} \cdot \alpha_{t-x}+\sum_{u=1}^{x} \theta_{u} \cdot\left(\alpha_{t-x+u}-\alpha_{t-x+u-1}\right)
$$

where

$$
\theta_{u} \equiv\left(1-\frac{u}{50}\right)^{B}, \quad B \geq 0
$$

The parameter $\alpha_{t}$ registers the time- $t$ level of productivity per work hour from cumulative technological progress - so that $\alpha_{t+1}-\alpha_{t}$ measures technological progress during year $t$. We estimate the parameter $B$, as well as $\alpha_{t}$ each $t$.

Consider formulas (9)-(10). If $B=0$, we have $\theta_{u}=1$ all $u$. Then component (9) equals $\alpha_{t}$. In other words, $B=0$ is the case from Section 2 with "general" technological progress.

If, on the other hand, $B=\infty$, we have $\theta_{u}=0$ all $u \geq 1$. Then component (9) equals $\alpha_{t-x}$. This is precisely Section 2's case of "specific" technological progress, in which only the level of productivity from technology when one starts work affects one's earnings.

In between these polar cases, $0<B<\infty$. If $B$ is near $0, \theta_{u}$ remains near 1 until experience is quite large; so, we approximate "general" technological progress. If $B=1$, the effect on one's wage from year-to-year technological progress diminishes linearly with one's experience, with progress midway through one's career affecting one's wages about 
half as much as cumulative progress at the outset. For $B$ much larger than, say, 5, only technological change in the first half-dozen years of one's career significantly affects one's productivity; so, we approximate Section 2's case of "specific" technological progress. As stated, $B$ is a parameter to be estimated.

The regression model's last component is regression error $\epsilon_{i e x t}$. The complete regression model for $\ln \left(w_{\text {iext }}\right)$ is

$$
\begin{array}{r}
\ln \left(w_{\text {iext }}\right)=\gamma_{0}^{e}+\gamma_{1}^{e} \cdot x+\gamma_{2}^{e} \cdot \frac{x^{2}}{10}+\gamma_{3}^{e} \cdot \frac{x^{3}}{100}+\gamma_{4}^{e} \cdot \frac{x^{4}}{1000} \\
+\theta_{0} \cdot \alpha_{t-x}+\sum_{u=1}^{x} \theta_{u} \cdot\left(\alpha_{t-x+u}-\alpha_{t-x+u-1}\right)+\epsilon_{\text {iext }}
\end{array}
$$

This paper estimates $(\vec{\gamma}, B, \vec{\alpha})$ using NLLS, treating the error as homoscedastic.

Outcomes. Tables 1-2 present preliminary results.

Table 1 provides parameter estimates for a specification including (11) and a second equation. Despite our sample's size, it lacks earnings observations for 1951-59, 1961-66, and years before 1950. To see the role of the latter, note that a 32 year old college graduate in 1950 began his career in 1940; hence, (11) utilizes $\alpha_{1940}, \ldots, \alpha_{1950}$ in estimating his wages from 1950. Alphas for years without wage observations are potentially very difficult to estimate. Table 1 employs a second equation to help as follows. Let $q_{t}$ be aggregative output per labor hour in year $t$. If we have a Cobb-Douglas aggregate production function, $q_{t}$ is proportional to labor's aggregative marginal product. The envelope theorem shows that the latter equals the marginal product of labor, hence the wage rate, throughout the economy; therefore, $\ln \left(q_{t}\right)$ should equal our $\alpha_{t}$ plus the $\log$ of the constant of proportionality between the average and marginal product of labor. Our second equation, accordingly, is

$$
\ln \left(q_{t}\right)=\bar{\alpha}+\alpha_{t}+\nu_{t}
$$

where $\nu$ is an iid error and $\bar{\alpha}$ is our additional constant.

Our data for $q_{t}$ is the Bureau of Labor Statistics time series on business output per hour 1947-2000 - see

$$
\text { http : //data.bls.gov/cgi-bin/dsrv . }
$$

This data has the shortcoming of not adjusting labor hours for "quality" — i.e., for experience, education, and cumulative embodied technological progress - as complete consistency with our model requires. Future drafts will employ a more sophisticated index. 


\section{Table 1. Selected Coefficient Estimates Regression Model (11)-(12): PUMS, CPS, and BLS Data}

\begin{tabular}{|c|c|c|c|c|c|c|}
\hline \multirow{3}{*}{$\begin{array}{l}\text { Para- } \\
\text { meters }^{a}\end{array}$} & \multirow{2}{*}{\multicolumn{2}{|c|}{$\begin{array}{l}\text { Aggregate the } \\
\text { Three Education } \\
\text { Categories }\end{array}$}} & \multicolumn{4}{|c|}{ Separate the Education Categories } \\
\hline & & & \multicolumn{2}{|c|}{$B^{A G G}$ Only } & \multicolumn{2}{|c|}{$B^{H S}, B^{S C}, B^{C}$} \\
\hline & $\begin{array}{l}\text { Ages } \\
25-55\end{array}$ & $\begin{array}{c}\text { Ages } \\
25-60\end{array}$ & $\begin{array}{l}\text { Ages } \\
25-55\end{array}$ & $\begin{array}{l}\text { Ages } \\
25-60\end{array}$ & $\begin{array}{l}\text { Ages } \\
25-55\end{array}$ & $\begin{array}{l}\text { Ages } \\
25-60\end{array}$ \\
\hline$\gamma_{0}^{S C}$ & & 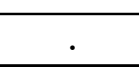 & .0643 & .0307 & .0605 & .0272 \\
\hline$\gamma_{0}^{C}$ & & - & .3160 & .2714 & .3112 & .2653 \\
\hline$\alpha_{1949}$ & 9.2188 & 9.2009 & 9.1506 & 9.1704 & 9.1531 & 9.1705 \\
\hline$\alpha_{1959}$ & 9.5909 & 9.5820 & 9.5052 & 9.5304 & 9.5152 & 9.5398 \\
\hline$\alpha_{1969}$ & 9.8599 & 9.8490 & 9.7658 & 9.7857 & 9.7825 & 9.8006 \\
\hline$\alpha_{1979}$ & 9.8684 & 9.8701 & 9.7741 & 9.8027 & 9.7849 & 9.8114 \\
\hline$\alpha_{1989}$ & 9.8750 & 9.8809 & 9.7848 & 9.8165 & 9.7878 & 9.8173 \\
\hline$\alpha_{1999}$ & 9.9148 & 9.9133 & 9.8150 & 9.8404 & 9.8144 & 9.8370 \\
\hline$B^{A G G}$ & .3269 & .2683 & .0889 & .0709 & 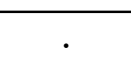 & . \\
\hline$B^{H S}$ & $\cdot$ & . & $\cdot$ & . & .0796 & .0681 \\
\hline$B^{S C}$ & & . & & . & .1018 & .1032 \\
\hline$B^{C}$ & & . & & . & .4482 & .3806 \\
\hline
\end{tabular}

a. Recall that $\gamma_{0}^{H S}=0$.

Table 1 presents three sets of outcomes, each replicated for workers of age 25-55 and 25-60. All columns jointly employ the PUMS, CPS, and BLS data. All six jointly estimate (11)-(12), with cross-equation restrictions.

In the first two columns, the dependent variable for (11) is weighted averages of log wages for (age, year) cells. Coefficients include a single set of gammas $-\gamma_{1}^{A G G}, \ldots, \gamma_{4}^{A G G}$ - and a single $B$, say, $B^{A G G}$. The second pair of columns has as dependent variables in (11) weighted averages of log wages for (age, year, education) cells. There is a full set of fourteen gammas, $\gamma_{1}^{H S}, \ldots, \gamma_{4}^{H S}, \gamma_{0}^{S C}, \ldots, \gamma_{4}^{S C}, \gamma_{0}^{C}, \ldots, \gamma_{4}^{C}$. The third pair of columns repeats the same dependent variable but allows separate parameters $B$ by education, i.e., $B^{H S}$, $B^{S C}$, and $B^{C}$. Table 1 presents only selected coefficient estimates for each specification.

Results are as follows. (i) All estimates of alpha show a generally diminishing rate of technological progress in the U.S. economy. For example, column 1 shows average productivity increases from technological progress of 37 percent for the decade 1949-59, 27 percent for 1959-69, 1 percent for 1969-79, 1 percent for 1979-89, and 3.5 percent for 1989-99. (ii) Estimates of $B$ are relatively low in all six columns. Consider $B=.33$ 
from column 1, for instance. The "weight" on technological progress for an individual just starting his career is $\theta_{0}=1$. In other words, current technological progress increases such an individual's personal productivity one-for-one. Twenty years later, the "weight" is

$$
\theta_{20}=\left(1-\frac{20}{50}\right)^{.33}=.84 .
$$

Hence, about half way through his career, a worker's productivity still incorporates 84 percent of current technological progress. After 30 years,

$$
\theta_{30}=\left(1-\frac{30}{50}\right)^{.33} \approx .74 .
$$

Even after 40 years, by which time the worker is probably at or near retirement,

$$
\theta_{40}=\left(1-\frac{40}{50}\right)^{.33} \approx .59 .
$$

(iii) Columns 3-6 associate large earning differences with education differences - men with some college earn 3-6 percent more than high school graduates; men with college earn 27-32 percent more than those with high school alone. (iv) Allowing education to directly affect wages changes our estimate of $B$ appreciably (i.e., compare columns 3-4 with 1-2); allowing different $B$ parameters for different education groups leads to a potentially interesting pattern with more specificity of technological progress for more educated men. The latter outcome is not robust in Table 2, however.

Table 2 drops equation (12) and studies results for (11) with separate education groups. The dependent variables are weighted averages of log wages for (age, year) cells. Again, we present only selected coefficient estimates.

Outcomes are as follows. (i) The gammas are quite similar in all columns. The table's addendum shows that productivity independent of technological progress peaks quite late in life - after 35 or more years of experience in every column. Hence, even in the complete absence of technological progress, workers would find their (real) wages reaching a maximum at age 54 or beyond. The second row of the addendum shows that independent of technological progress, high school graduates would enjoy over their careers wage increases of about 90 percent from the accumulation of experience alone; similar gains are about 100 percent for men with some college, and about 110 percent for college graduates. Only high school graduates find their wages declining by 5 percent or more between their earning peak and age 62. (ii) As above, the estimates of alpha show large wage increases from technological progress 1949-69 and much smaller changes thereafter. In fact, different 


\section{Table 2. Selected Coefficient Estimates Regression Model (11): PUMS and CPS Data; Individual Education Groups}

\begin{tabular}{|c|c|c|c|c|c|c|}
\hline \multirow{3}{*}{$\begin{array}{l}\text { Para- } \\
\text { meters }^{a}\end{array}$} & \multicolumn{6}{|c|}{ Education Category } \\
\hline & \multicolumn{2}{|c|}{ High School } & \multicolumn{2}{|c|}{ Some College } & \multicolumn{2}{|c|}{ College/more } \\
\hline & $\begin{array}{l}\text { Ages } \\
25-55\end{array}$ & $\begin{array}{l}\text { Ages } \\
25-60\end{array}$ & $\begin{array}{l}\text { Ages } \\
25-55\end{array}$ & $\begin{array}{l}\text { Ages } \\
25-60\end{array}$ & $\begin{array}{l}\text { Ages } \\
25-55\end{array}$ & $\begin{array}{l}\text { Ages } \\
25-60\end{array}$ \\
\hline$\gamma_{1}^{e}$ & .0930 & .0874 & .1093 & .1124 & .1168 & .1244 \\
\hline$\gamma_{2}^{e}$ & -.0431 & -.0380 & -.0520 & -.0548 & -.0522 & -.0607 \\
\hline$\gamma_{3}^{e}$ & .0102 & .0085 & .0119 & .0131 & .0106 & .0142 \\
\hline$\gamma_{4}^{e}$ & -.0010 & -.0008 & -.0011 & -.0012 & -.0008 & -.0013 \\
\hline$\alpha_{1949}$ & 9.2222 & 9.2691 & 9.2785 & 9.2563 & 9.3820 & 9.3401 \\
\hline$\alpha_{1959}$ & 9.6012 & 9.6370 & 9.6599 & 9.6558 & 9.7704 & 9.7233 \\
\hline$\alpha_{1969}$ & 9.8078 & 9.8218 & 9.8613 & 9.8521 & 10.0232 & 9.9927 \\
\hline$\alpha_{1979}$ & 9.8349 & 9.8483 & 9.8603 & 9.8520 & 10.0188 & 9.9966 \\
\hline$\alpha_{1989}$ & 9.7536 & 9.7790 & 9.8481 & 9.8405 & 10.1387 & 10.1248 \\
\hline$\alpha_{1999}$ & 9.7382 & 9.7441 & 9.8770 & 9.8561 & 10.2473 & 10.2230 \\
\hline$B$ & .3961 & .0861 & .1974 & .0813 & .1284 & .2682 \\
\hline \multicolumn{7}{|c|}{ Addendum: Details on "Productivity Independent of Technological Progress" } \\
\hline $\begin{array}{l}\text { Experience for } \\
\text { max earn }\end{array}$ & 36 & 37 & 37 & 35 & 50 & 36 \\
\hline $\begin{array}{c}\text { Max } \ln (\text { earn }) \text { up to } \\
\text { age } 62 \text { less start } \ln (\text { earn })\end{array}$ & .9144 & .9040 & .9981 & .9978 & 1.1266 & 1.0780 \\
\hline $\begin{array}{l}\ln (\text { earn }) \text { at age } 62 \\
\text { less start } \ln (\text { earn })\end{array}$ & .8479 & .8675 & .9724 & .9514 & 1.1266 & 1.0602 \\
\hline
\end{tabular}

a. Recall that $\gamma_{0}^{e}=0$.

education groups have different experiences after 1969. Male high school graduates register a 3 percent gain 1969-79 but a 10 percent loss 1979-99; men with some college have no wage change from technological progress 1969-99; and, male college graduates have no change 1969-79 but a gain of 20-25 percent 1979-99. This pattern is familiar from the literature (e.g., Bound and Johnson [1992]), and it potentially complicates the interpretation of Table 1. (iii) Estimates of $B$ rise with education across columns 2, 4, and 6 . This is reminiscent of Table 1, columns 5-6. However, estimates of $B$ decline with education across columns 1,3 , and 5 . Our verdict at this point is that estimates of $B$ are all quite 
small but lack any other robust pattern.

Conclusions. Our tentative conclusions at this point include the following.

(1) Estimates of gamma from Table 2 imply that gains in human capital from experience drive a worker's wage upward until well past the midpoint of his career. Proposition 1, Section 3, then indicates that "aging" of the work force should boost an economy's "average productivity per worker independent of technological progress."

(2) Estimates of $B$ are uniformly low in Tables 1-2. This implies that technological progress is "general" rather than "specific." According to Proposition 2, Section 3, therefore, "aging" of the work force is unlikely to have a large detrimental effect on "augmentation of worker productivity from technological change."

(3) Our low estimate of $B$ also points to the desirability of a specification of the lifecycle model of household behavior that incorporates the risk of unknown rates of technological progress during each household's life span.

(4) Since 1970 only college educated men seem to have benefited from technological progress. Some authors suggest that technological progress has become specific to education (e.g., Bound and Johnson [1992]). If correct, this would invalidate, or at least greatly complicate, attempts to provide meaningful linear aggregates of labor hours from different workers. ${ }^{4}$

(4) Technological progress, as registered by changes $\alpha_{t+1}-\alpha_{t}$, is a latent variable in equation (11), presenting challenges for estimation. In fact, estimates of $\alpha_{t}$ for years in which we lack wage data tend to be erratic. Equation (12) helps; however, for Table 2's analysis, finding additional data sources is a priority.

\section{Conclusion}

This work is preliminary; nevertheless, results at this stage point to several tentative conclusions. First, "aging" of the U.S. work force seems more likely to increase aggregate productivity - by raising the proportion of laborers with sizable accumulations of human capital from experience - than to decrease it - by slowing the adoption rate for innovations. Our preliminary estimates seem to imply that the latter effect is of modest magnitude. Second, since our preliminary estimates point to "general" rather than "specific" technological progress (recall Section 2's definitions), each household faces a problem

4 An alternative possibility is that endogeneity of education choices generates selection biases over time across education groups (e.g., Laitner [2000]), and that this plays a role in determining the pattern of Table 12's alphas. 
of having to predict the course of technological progress over its life span. This means that households face more risk than otherwise, and it complicates the specification of the lifecycle model that analysts should employ. Third, when we disaggregate across education groups, the groups seem to show quite unequal benefits from technological progress after 1980, and this may lead to further challenges in modeling household behavior. 


\section{Bibliography}

[1] Becker, Gary S., "A Theory of Social Interactions," Journal of Political Economy 82, no. 6 (November 1974): 1063-1093.

[2] Borsch-Supan, Axel, "Global Aging: Issues, Answers, More Questions." Working Paper WP 2004-084, University of Michigan Retirement Research Center, June 2004. [www.mrrc.isr.umich.edu]

[3] Bound, John, and Johnson, George, "Changes in the Structure of Wages in the 1980's: An Evaluation of Alternative Explanations," American Economic Review 82, no. 3 (June 1992): 371-392.

[4] Burmeister, Edwin, and Dobell, Rodney, "Disembodied Technological Change with Several Factors," Journal of Economic Theory 1, no. 1 (June 1969): 1-8.

[5] Johnson, William R., "Vintage Effects in the Earnings of White American Men," The Review of Economics and Statistics 62, no. 3 (August 1980): 399-407.

[6] Laitner, John, "Earnings within Education Groups and Overall Productivity Growth," Journal of Political Economy 108, no. 4 (August 2000): 807-832.

[7] Modigliani, Franco, "Life Cycle, Individual Thrift, and the Wealth of Nations," American Economic Review 76, no. 3 (June 1986): 297-313.

[8] Nyce, Steven A., and Schieber, Sylvester J. The Economic Implications of Aging Societies. Cambridge: Cambridge University Press, 2005.

[9] Solow, Robert M., "A Contribution to the Theory of Economic Growth," Quarterly Journal of Economics 70, no. 1 (February 1956): 65-94.

[10] Solow, Robert M., "Technical Change and the Aggregate Production Function," Review of Economics and Statistics 39, no. 3 (August 1957): 312-320.

[11] Solow, Robert M., "Investment and Technological Progress," in Kenneth Arrow, Samuel Karlin, and Patrick Suppes, eds., Mathematical Methods in the Social Sciences 1959. Stanford, CA: Stanford University Press, 1960. 


\section{Appendix}

Proof of Proposition 1. Let

$$
\mu(s, t) \equiv \frac{N_{t} \cdot e^{-n \cdot s}}{\int_{0}^{R} N_{t} \cdot e^{-n \cdot s} d s} .
$$

Notice $\mu(s, t)>0$. We have

$$
\frac{d A_{t}^{I}}{d n}=-\left[\int_{0}^{R}(s-\bar{s}) \cdot p(s) \cdot \mu(s, t) d s\right] .
$$

We show the term [.] is non-negative.

We have

$$
\begin{aligned}
\int_{0}^{R} & (s-\bar{s}) \cdot p(s) \cdot \mu(s, t) d s \\
\quad= & \int_{0}^{\bar{s}}(s-\bar{s}) \cdot p(s) \cdot \mu(s, t) d s+\int_{\bar{s}}^{R}(s-\bar{s}) \cdot p(s) \cdot \mu(s, t) d s \\
\quad> & \int_{0}^{\bar{s}}(s-\bar{s}) \cdot p(\bar{s}) \cdot \mu(s, t) d s+\int_{\bar{s}}^{R}(s-\bar{s}) \cdot p(\bar{s}) \cdot \mu(s, t) d s \\
= & \int_{0}^{R}(s-\bar{s}) \cdot p(\bar{s}) \cdot \mu(s, t) d s \\
= & p(\bar{s}) \cdot \int_{0}^{R}(s-\bar{s}) \cdot \mu(s, t) d s \\
= & 0 .
\end{aligned}
$$

This completes the proof. 


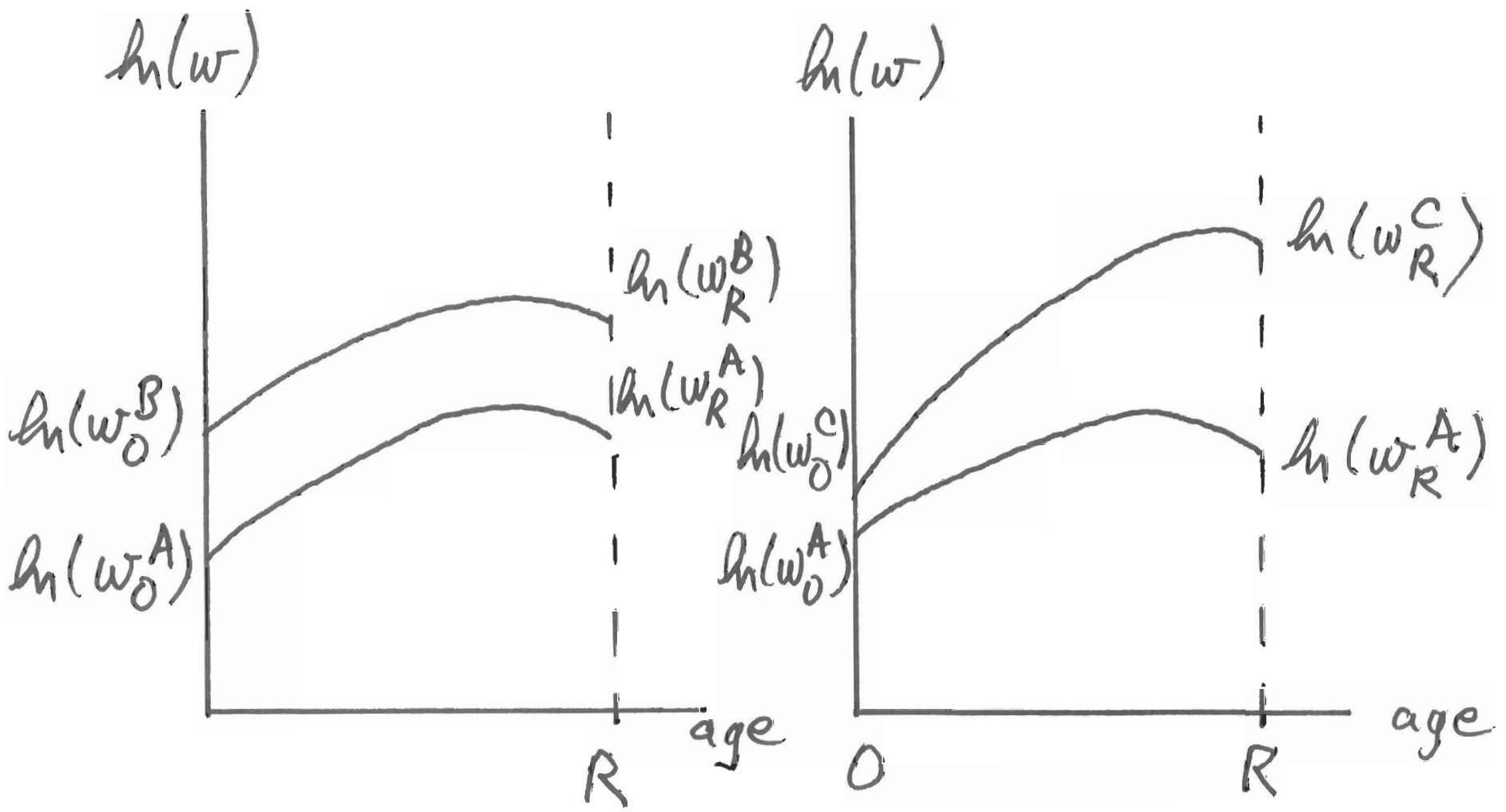

Figure 1. Lifelime wage profiles with general (right) and specilic (lelt) technological progress 


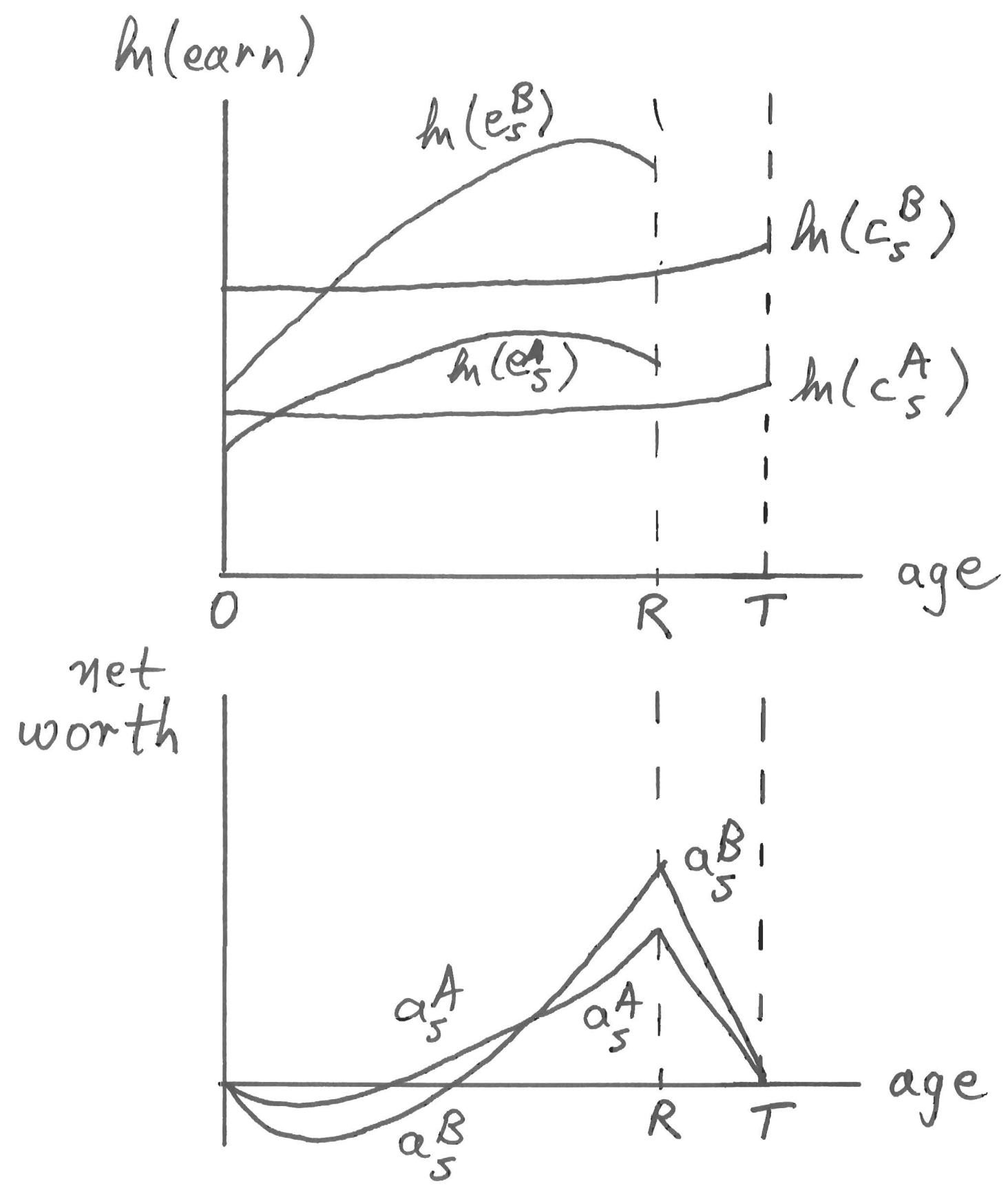

Figure 2. Household earnings, consumption, and assets; case with general technological progress

22 
$\ln (\operatorname{earn})$

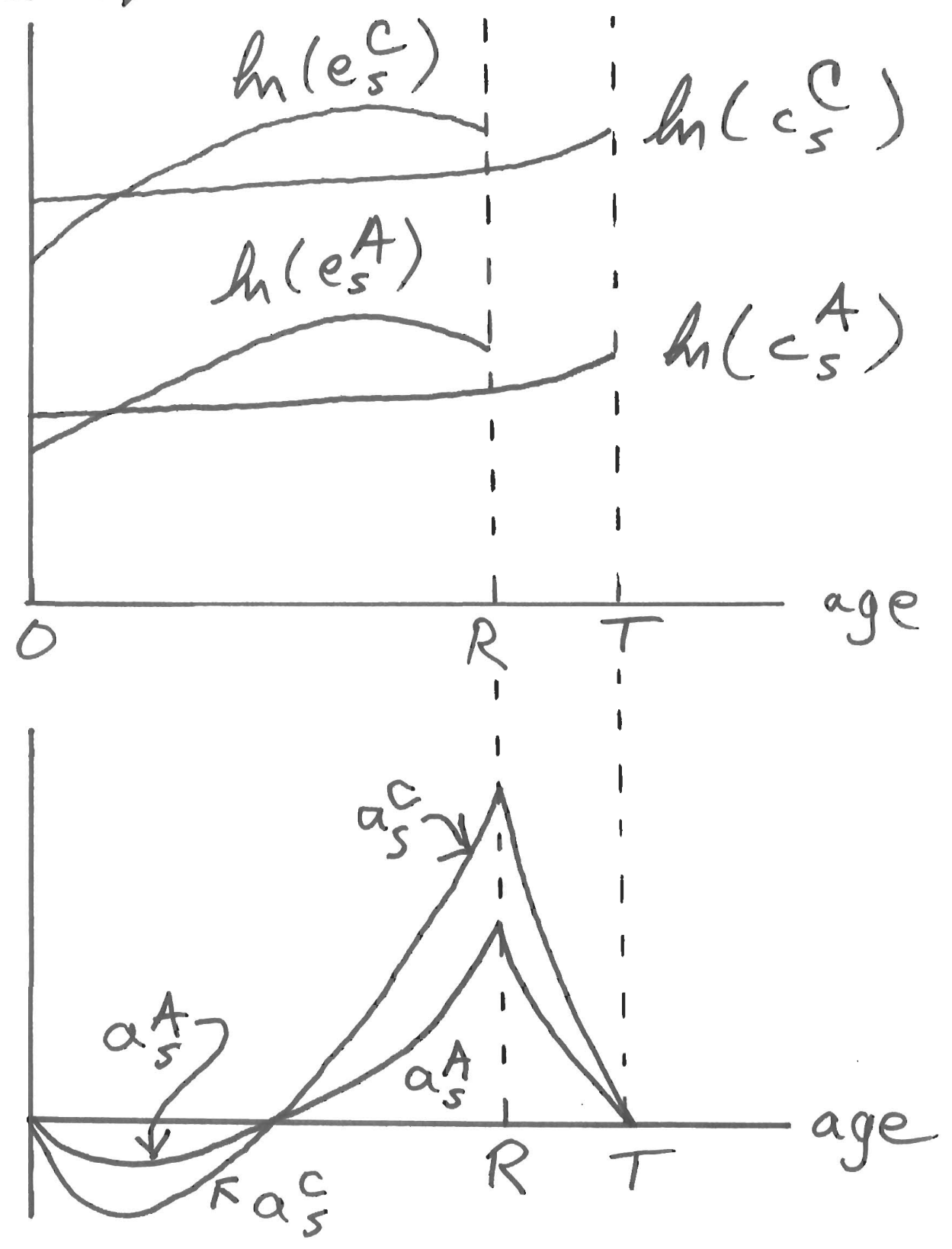

Figure 3. Household earnings, consumption, and assets; case with specific technological progress

23 